\title{
Spectrophotometric determination of total phenol in fish muscle after in- situ derivatization and reverse phase dispersive liquid- liquid microextraction
}

\author{
Morteza Ziyaadini $^{1}$, Mansoor Khordegir ${ }^{1}$ \\ 1- Department of Marine Chemistry, Faculty of Marine Science, Chabahar Maritime University, \\ P.O. Box 98617-85553, Chabahar, Iran
}

Received: August 2016

Accepted: March 2017

(C) 2017 Journal of the Persian Gulf. All rights reserved.

\begin{abstract}
Reverse phase dispersive liquid- liquid microextraction (RP- DLLME) coupled with spectrophotometry is introduced for the detection of total phenol in the muscle tissue of fishes, such as Sphyraena genie, Otolithes ruber, Rastrelliger kangurta, Lutjanus johnii and Barbus Subquin Cunciatus. Phenols in fish tissues were extracted by ultrasonic bath and derivatization with 4- aminoantipyrine. The factors influencing on the extraction efficiency, including type and volume of extracting solvent, extraction time, concentration of 4- aminoantipyrine, derivatization reaction temperature and centrifugation rate and time were evaluated. The used protocol was found to yield a linear calibration curve in the concentration range of 0.4 and 1.6 mg L-1 with a limit of detection of $0.012 \mathrm{mg} \mathrm{L}-1$. The enrichment factors founded 83 -fold. The SPSS was utilized for statistical analysis. The technique has been successfully used for the analysis of total phenols in fish species from several locations in Chabahar Bay.
\end{abstract}

Keywords: Reverse phase dispersive liquid- liquid microextraction, spectrophotometry, fish muscle, 4- aminoantipyrine

\section{Introduction}

Phenolic compounds are one of the most important pollutants of the environment. They are used in different manufacturing processes for products, such as plastics, dyes, synthetic rubber and household detergents (Khezeli \& Daneshfar, 2015; Zhong et al. 2011). Because of their toxicity and carcinogenicity, many phenolic compounds are included in the list of priority pollutants in many

*Email: M.ziyaadini@cmu.ac.ir countries and monitored. For example, the European Community (EC) determines a legal tolerance level of $0.1 \mu \mathrm{g} / \mathrm{L}$ of each phenolic compound and $0.5 \mu \mathrm{g} / \mathrm{L}$ of total phenolics pollutants. So, establishing a simple, rapid and environment friendly technique for determining of such pollutants in environment and fish tissues is very crucial (Hashemi \& Najari, 2018). For the detection of phenolic analytes different analytical technique, such as micellar electrokinetic chromatography (Ghorbanpour et al. 2014), capillary electrochromatography (Ghorbanpour et al. 2014), capillary electrophoresis coupled by ultraviolet (UV) 
detection or mass spectrometry (Feng et al. 2009; Blanco et al. 2005), high performance liquid chromatography (HPLC) (Hashemi \& Najari, 2018; Feng et al. 2009) and spectrophotometry (Nassiri et al. 2014) has been proposed.

In analytical methods, sample pretreatment is generally needed for detection of trace analytes in real sample. Up to now, different extraction methods have been used to extract phenolic analytes from real samples, including ionic liquid dispersive liquidliquid microextraction (Jiang et al. 2011), activated carbon (Li et al. 2009), air- assisted liquid- liquid solid phase extraction (SPE) (Masque et al. 2000), ion- exchange (Akhtar et al. 2006), dispersive liquidliquid microextraction (Yang et al. 2017), ionic liquid three- phase liquid- liquid- liquid solvent microextraction (Guo et al. 2011), solid - phase microextraction (SPME) (Peñalver et al. 2002) and molecularly imprinted stir bar sorptive extraction (Hashemi \& Najari, 2018). Rezaee and co-workers have introduced a novel microextraction method, referred to as dispersive liquid- liquid microextraction (DLLME) (Rezaee et al. 2006). The advantages of this technique include low cost, short extraction time and high recovery. This method has been used for microextraction of organophosphorus pesticides, phenols and thiamine in aqueous samples (Jiang et al. 2011; Berijani et al. 2006; Mohsen et al. 2010). DLLME is based on a ternary component solvent system. In this technique, usually, a small volume of organic solvent is dispersed into fine droplets in the sample solution with aid of a water miscible solvent as disperser. After phase separation achieved with centrifugation, the organic solvent is solidified at the conical bottom of centrifuge tube as a micro- drop which can be withdrawn using a microsyringe (Nassiri et al. 2018; Hashemi et al. 2017).

In this research, a new generation of DLLME, named as reversed phase DLLME was applied for pre- concentration and extraction of total phenols. In this protocol, a water phase is dispersed in organic solvent using disperser solvent. Thus, the sedimented phase which is a water microliter can be subjected to spectrophotometry directly for determination of total phenols (Ziyaadini et al. 2016). The objective of this research is to develop the potential application of RP- DLLME for the microextraction of total phenols in fish muscle followed by determination with spectrophotometry for the first time in Chabahar Maritime University Bay research facilities.

\section{Materials and Methods}

\subsection{Reagents}

Phenol was purchased of Sigma- Aldrich (St. Louis, Mo, USA). All other salts, acids and organic solvents used as analytical grade and were obtained of Merck KGaA (Germany) and applied as received. Milli- $Q^{\circledR}$ water $(18.3 \mathrm{M} \Omega / \mathrm{cm})$ was utilized throughout the runs. Stock solution of phenol (with concentration of $1000 \mathrm{mg} / \mathrm{L}$ ) was prepared with dissolving the proper amount of phenol in $n$ - hexanedichloromethane (50:50). Concentration of total phenol in real sample was calculated with standard increase method. For determination of total phenol in fish muscle, the concentration of $0.5,1.0,1.5,2.0$ $\mathrm{mg} / \mathrm{L}$ of the analyte in optimum amount of 4- AAP was separately added to $1 \mathrm{~g}$ of dried fish muscle that dissolved in $4 \mathrm{~mL}$ of $\mathrm{n}$ - hexane- dichloromethane $(50: 50 \mathrm{v} / \mathrm{v})$. Then, concentrations of phenol in fish muscle are determined.

The SPSS (version 22) wereutilized for statistical investigation. All data analyzed for normal distribution (Shapiro- Wilk) and two- way analysis of variance (ANOVA) applying SPSS software (at $95 \%$ confidence level).

\subsection{Apparatus}

A UNICO S2100 Vis spectrophotometer (china) at wavelength of $510 \mathrm{~nm}$ coupled by $100 \mu \mathrm{L}$ quartz microcells (model Q-01701, Stara company, UKZ) was applied for spectrophotometric detection of phenol. Model 340 i WTW (Germany) pH meter was used for detection of pHs. In Figure 1, the absorption 
spectra of $1000 \mu \mathrm{g} / \mathrm{L}$ standard of phenol against blank reagent.

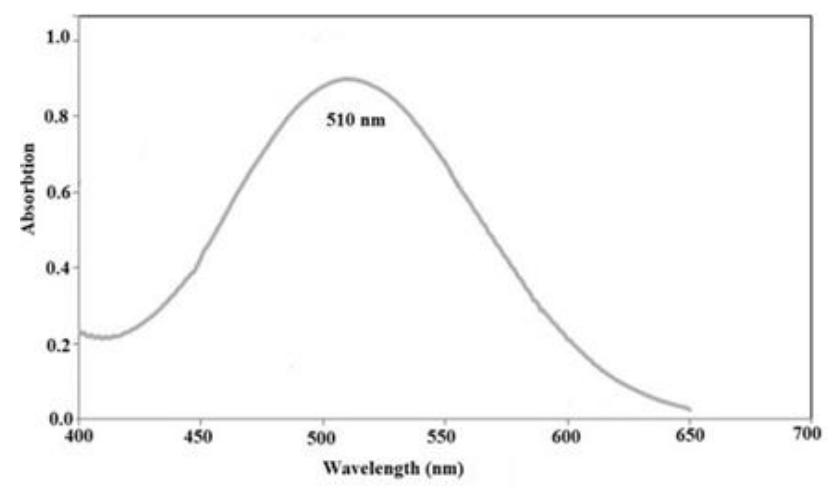

Fig 1: Absorption spectra for derivatization phenol by 4- AAP

\subsection{Ultrasonic Extraction}

The extraction of phenol of fish muscle was performed using the standard of EPA 3550C. In this method, $1 \mathrm{~g}$ of the dried fish muscle sample was spiked to $5.0 \mathrm{~mL}$ of dichloromethane- $\mathrm{n}$ - hexane (50: $50, \mathrm{v} / \mathrm{v})$. With sonication for $15 \mathrm{~min}$ applying an ultrasonic bath, the mixture was shaken, then centrifuged for $15 \mathrm{~min}$ at $3500 \mathrm{rpm}$, the supernatant decanted into $15 \mathrm{~mL}$ conical glass sample tube and preserved for the next step.

\subsection{RP- DLLME and Derivatization Protocol}

Fifty $\mathrm{mL}$ of standard solution including, 1000 $\mu \mathrm{g} / \mathrm{L}$ of phenol in $\mathrm{n}$ - hexane- dichloromethane (50:50 $\mathrm{v} / \mathrm{v}$ ) or $50 \mathrm{~mL}$ of real sample solution, obtained from ultrasonic extraction phase was placed in the test tube. An aliquot of $300 \mu \mathrm{L}$ of acetone as dispersive solvent and $50 \mu \mathrm{L}$ of $0.7 \mathrm{~mol} / \mathrm{L} \mathrm{NaOH}$ (the extraction solvent) was added and rapidly introduced to the diluted sample to form a cloudy solution. Next, the mixture was centrifuged at $4000 \mathrm{rpm}$ for $5 \mathrm{~min}$. The sedimented phase was removed with a $100 \mu \mathrm{L}$ microsyringe and mixed with $50 \mu \mathrm{L}$ of $0.9 \mathrm{w} / \mathrm{v} 4-4$ $\mathrm{AAP}$ and $50 \mu \mathrm{L}$ of $1.4 \% \quad \mathrm{w} / \mathrm{v}$ potassium peroxodisulfate, adjusting $\mathrm{pH}$ to 9.5 with addition of $0.1 \mathrm{~mol} / \mathrm{L} \mathrm{HCl}$ solution. The solution was shaken in a $30{ }^{\circ} \mathrm{C}$ water bath for $10 \mathrm{~min}$ until the reddish- brown color formed. Finally, $100 \mu \mathrm{L}$ of the water phase (extraction solvent) for determination of total phenols was introduced to UV-Vis spectrophotometry and read at wavelength of 510 .

\section{Results and discussion}

3.1. Optimization of RP- DLLME for Phenol Extraction

To investigate the RP- DLLME pre-concentration operating parameters for phenols analysis, factors which could affect the RP- DLLME enrichment were investigated in $1000 \mu \mathrm{g} / \mathrm{L}$ of phenol.

\subsection{Optimization of derivatization reaction}

Derivatization of phenols using 4- AAP for UVVis detection was introduced by Emerson (1943). This technique is based on the oxidative coupling of phenols using 4- AAP in the presence of an oxidant to from antipyrine dyes, the concentration of that can be readily determined with UV-Vis. In the research, derivatization reaction is performed before the RPDLLME protocol (Figure 2a). The use of colorimetric techniques has been reported for following the reaction of phenol by 4- AAP, either unsubstituted or ortho- or meta- substituted using halogens or methoxy, carboxy or sulfonate groups as seen in Figure 2b. Production of dyes is carried out in the presence of oxidants and our research indicated which potassium peroxodisufate is superior to other suggested reagents (Nassiri et al. 2014; Ziyaadini et al. 2016). The reaction at the $\mathrm{pH}$ of 9.5 leads to the generation of stable reddish- brown colored antipyrine dyes readable by spectrophotometry in water solution at wavelength of $510 \mathrm{~nm}$ (Nassiri et al. 2014; Ziyaadini et al. 2016). 


\subsection{Effect of 4- Aminoantipyrine (4- AAP) 3.4. Effect of Derivatization Reaction Temperature} Concentration

The concentration effect of 4- AAP on dye production was studied in range $0.01-0.1 \mathrm{~mol} / \mathrm{L}$. It was found that the production of complex is quantitative for concentration more than $0.05 \mathrm{~mol} / \mathrm{L}$ of 4-AAP, further runs performed with saturation of the samples by $4-$ AAP.
The effect of temperature of derivatization reaction was studied. Absorption of phenols from organic phase significantly increased with increasing the parameter up to $27^{\circ} \mathrm{C}$ and became stationary after that.<smiles>c1ccccc1</smiles>

B<smiles>Cc1c(N)c(=O)n(-c2ccccc2)n1C</smiles>

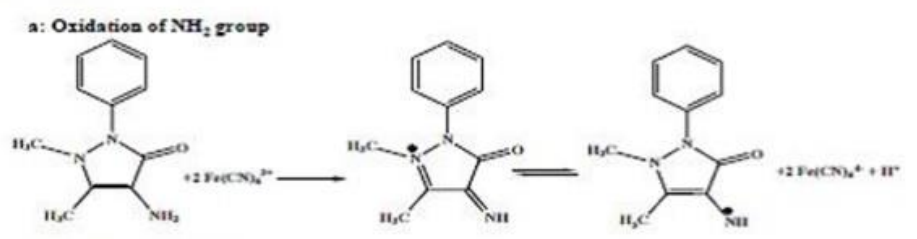

b: electropbilic attack
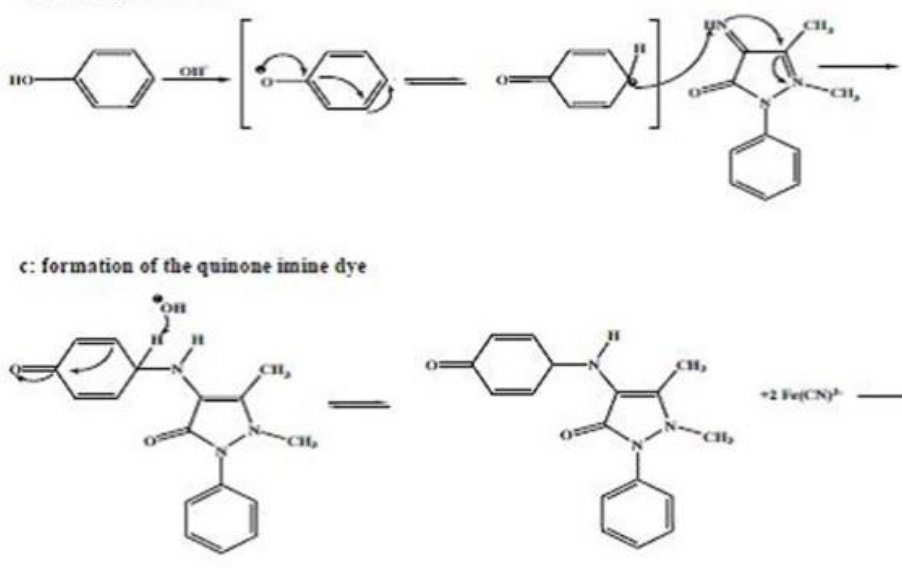

-2 Veicry
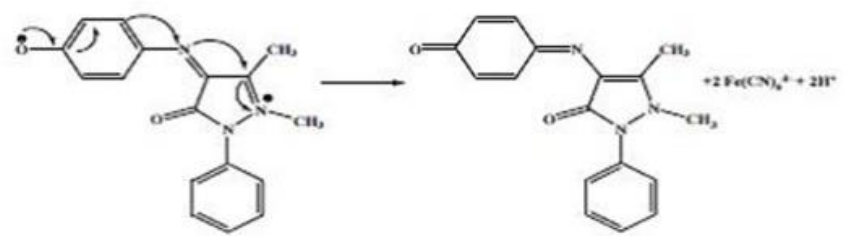

Fig 2.a: Reaction scheme for phenol treated with 4- AAP, b. production scheme of dyes in the presence of proper of oxidants a standard of phenols in organic media. 


\subsection{Effect of Concentration of Extraction Solvent}

Phenolic analytes are present in hydrophilic salt in the alkaline condition (Liu et al. 2013). So, phenolic compounds can be transformed from organic phase to their alkaline aqueous phase. $50 \mu \mathrm{L}$ of sodium hydroxide using various concentrations $(0.1-1.0 \mathrm{M})$ was utilized for analysis the spiked blank sample. The results are given in Figure 3. By increasing the extraction solvent volume from 0.1 to $1.0 \mathrm{M}$, the absorbance intensity hiked, but when the concentrations of $\mathrm{NaOH}$ exceeded beyond 0.7 to 1.0 $\mathrm{M}$, the absorbance intensity decreased. This is because optimum $\mathrm{pH}$ changed from that proposed for RP-DLLME technique with increase in the concentration of $\mathrm{NaOH}$ (the reason for the sharpness of the curve after the optimal value). Higher extraction efficiencies were achieved by a $0.7 \mathrm{M}$ $\mathrm{NaOH}$ and then decrease occurred (Figure 3).

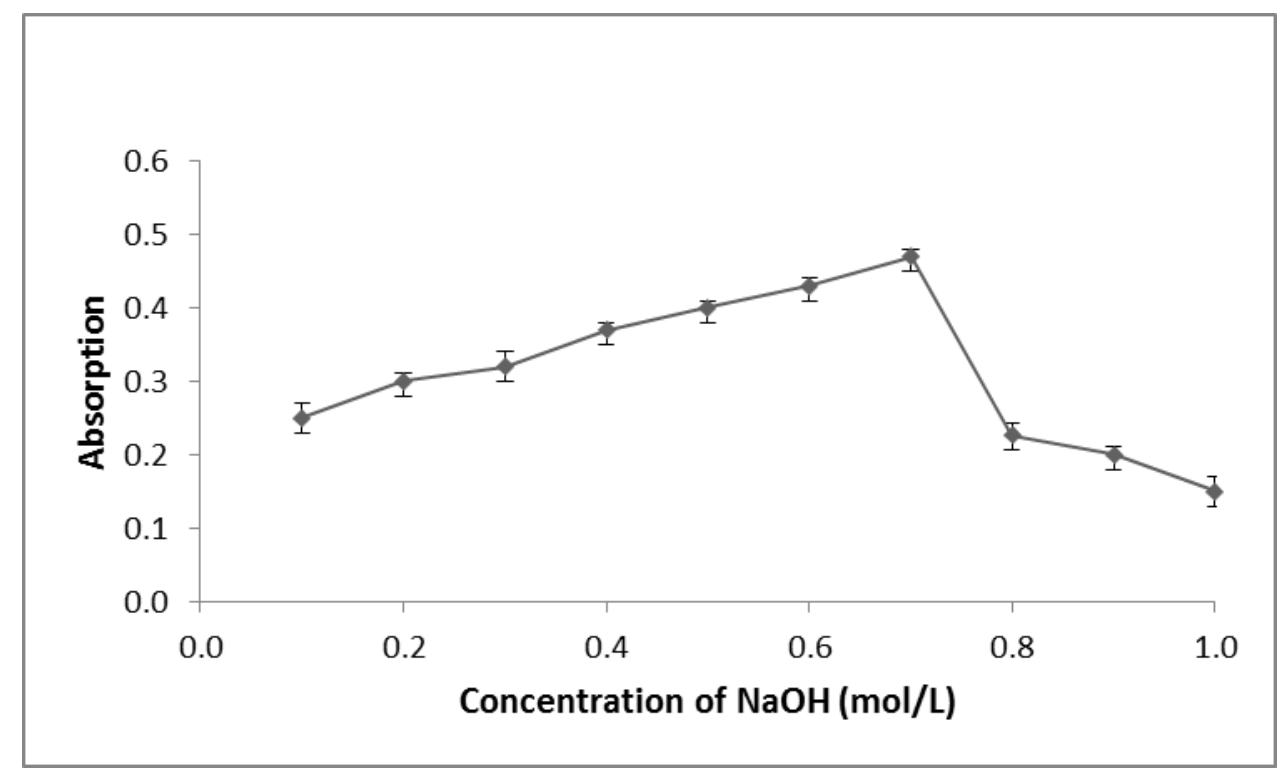

Fig 3: Effect of concentration of $\mathrm{NaOH}$ as extraction solvent on absorption intensity

\subsection{Effect of Concentration of Extraction Solvent}

Different volumes of $0.7 \mathrm{M} \mathrm{NaOH}$ solution between 30 and $80 \mu \mathrm{L}$ in $5 \mu \mathrm{L}$ intervals were subjected to RP-DLLME. When the volume of the extraction solvent was increased from 30 to $50 \mu \mathrm{L}$, the increase in the absorbance was not remarkable, however, with the volume over $50 \mu \mathrm{L}$, no distinct changes on the absorbance occurred., thus in the subsequent experiment a volume.

\subsection{Effect of Disperser Solvent}

The water as extraction solvent is dispersed as very fine droplets in the organic phase using a moderately polar disperser. The dispersed solvent should be miscible by the solvent extraction and the extraction solvent and the organic phase. Therefore, ethanol, acetonitrile, acetone and ethyl acetate as disperser solvents were tested. Ethanol distinguished the quantitative extraction of total phenol from organic phase (Figure 4).

This is probably because of ethanol is a polar aprotic solvent with relatively high dielectric constant. Also, the disperser solvent has low surface tension and high surface activity. 


\subsection{Effect of Volume of Disperser Solvent}

The volumes of disperser solvent were investigated to improve the recoveries of total phenols. The increase of the disperser volume (100$800 \mu \mathrm{L})$ slightly improved RP- DLLME efficiency of analytes to $300 \mu \mathrm{L}$, but above this volume, the absorption remains constant as shown in Figure 5 (based on experimental result). Based on the results of the DLLME optimization study, 300 was selected as optimal volume of disperser solvent.

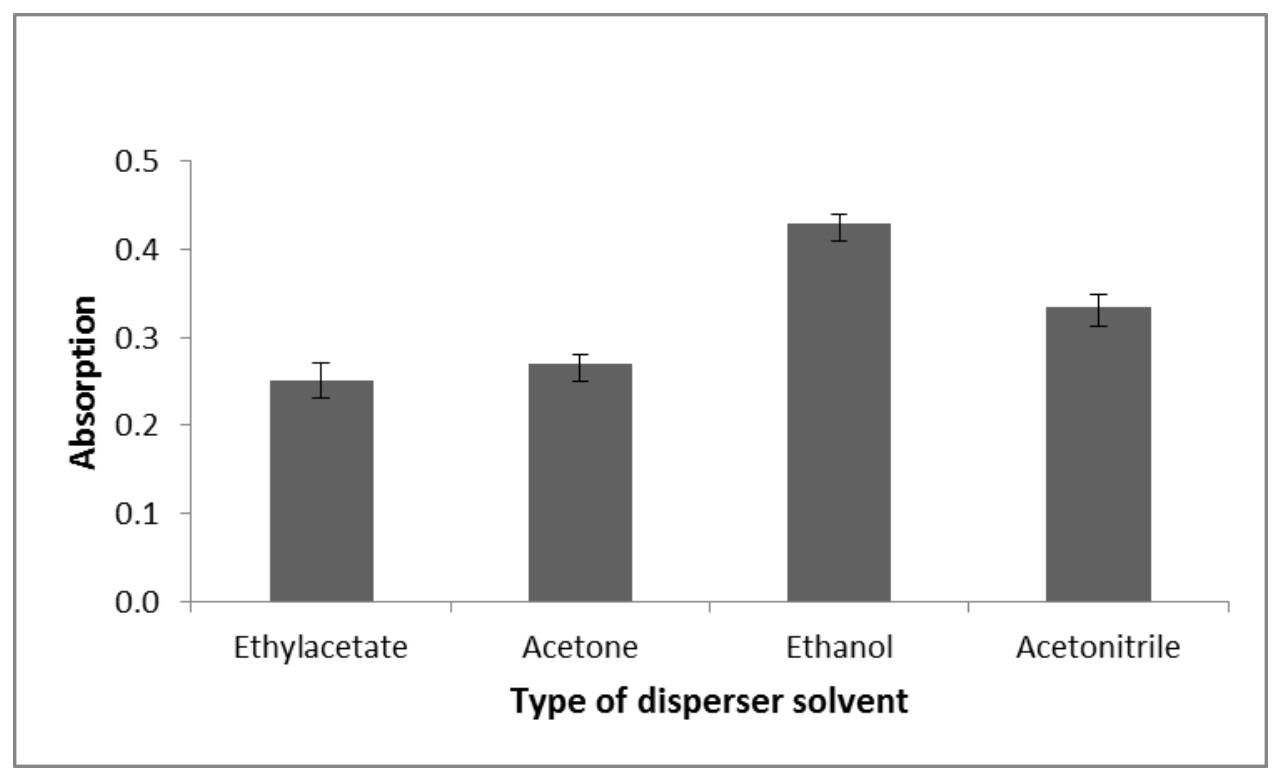

Fig 4: Effect of type of disperser solvent on absorption intensity

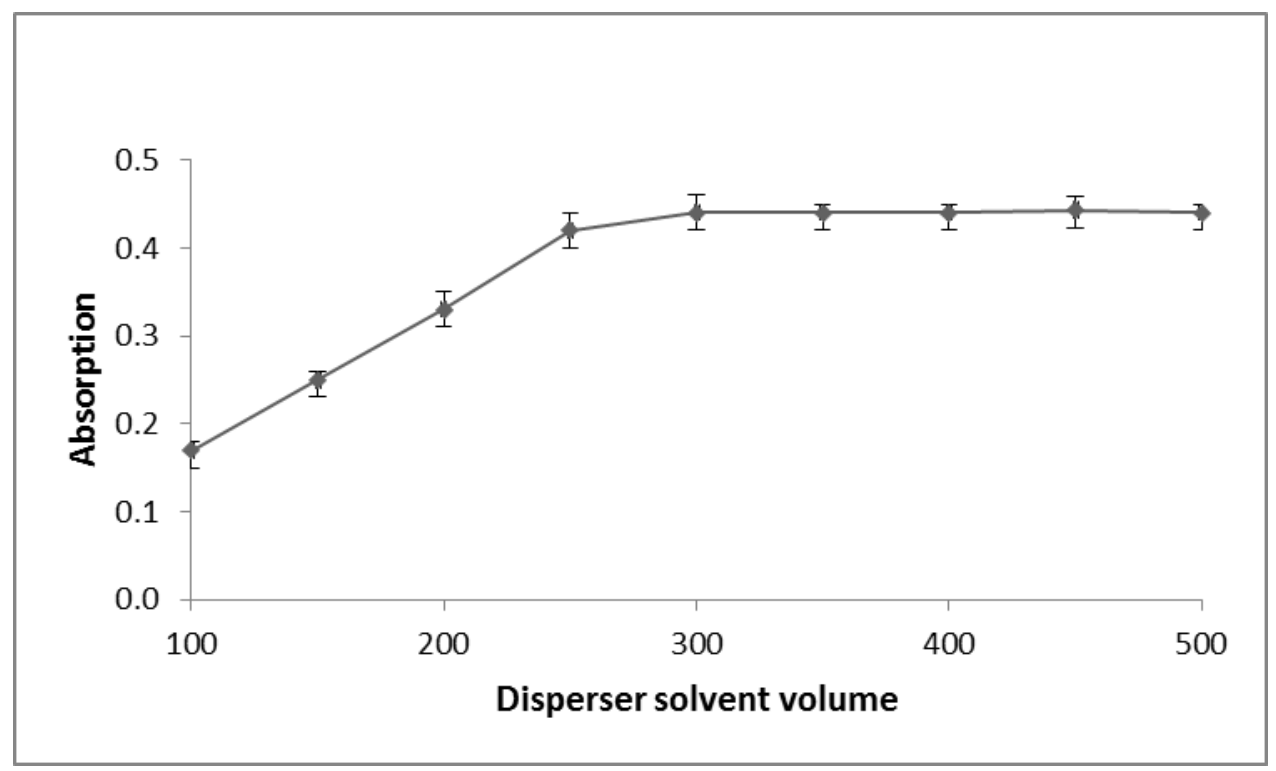

Fig 5: Effect of disperser solvent volume on absorption intensity 


\subsection{Effect of Extraction Time}

The time factor was investigated in the range of 1$10 \mathrm{~min}$. The extraction efficiency reached its maximum value at $3 \mathrm{~min}$ and remained constant afterwards. Thus, 3 min was selected to all runs.

\subsection{Effect of Centrifugation Rate and Time}

The effect of centrifugation rate and time on the extraction efficiency was investigated in the range of 1000- $4000 \mathrm{rpm}$ and 1-10 $\mathrm{min}$, respectively. A centrifugation time of $2 \mathrm{~min}$ and $2000 \mathrm{rpm}$ as centrifugation rate were selected for the further runs as complete phase separation occurred and became constant after that.

\subsection{Analytical Performance}

\subsubsection{Linearity, limit of detection and enrichment} factor

Under optimum condition, the calibration curve was linear over a concentration range of $0.02-5 \mathrm{mg}$ L-1 for phenol. The least square equation above the dynamic linear range is

$\mathrm{A}=0.1232 \mathrm{C}+0.0222$ with $\mathrm{r}^{2}=0.9896$

Where $\mathrm{C}$ and $\mathrm{A}$ are the concentration of total phenol response.

The enrichment factors (EFs) and recoveries were achieved with Eqs. (1) and (2), respectively (Hashemi et al. 2017).

$$
\begin{aligned}
& \mathrm{EF}=\mathrm{C}_{\text {org }} / \mathrm{C}_{\mathrm{aq}} \\
& \mathrm{R}=\left(\mathrm{C}_{\text {org }} \times \mathrm{V}_{\text {org }}\right) /\left(\mathrm{C}_{\mathrm{aq}} \times \mathrm{V}_{\mathrm{aq}}\right) \times 100 \%=\mathrm{EF} \times \\
& \left(\mathrm{V}_{\text {org }} / \mathrm{V}_{\mathrm{aq}}\right) \times 100 \%
\end{aligned}
$$

Where EF, R, Caq, Corg, Vorg and Vaq is the enrichment factor, recovery, initial concentration of analyte in the sample, sediment phase (extraction solvent volume) and water sample volume, respectively.

Under optimal experimental parameter, the limit of detection (LOD) of the investigated protocol for phenol was calculated $12 \mu \mathrm{g} / \mathrm{Kg}$ for the analyte based on the 3 $\mathrm{Sd} / \mathrm{m}$ criteria; in which $\mathrm{Sd}$ is the standard deviation of seven consecutive measurements of the blank and $\mathrm{m}$ is the slope of calibration curve. The enrichment factors (defined as Eqs. 1) founded 83 -fold. Table 1 compares the characteristic data of the proposed technique with those utilizing solid phase extraction for phenol compounds determination, reported in the literature.

\subsubsection{Determination of Phenols in Fish Muscle}

The studied area was selected in Chabahar Bay in this research based on the high probability of phenol contamination in the area. Fish specimens were collected in winter 2018 from all the sampling stations and then, placed in a plastic bag in the ice container and transferred to the laboratory and stored in the freezer at $-20{ }^{\circ} \mathrm{C}$ until analysis. During the analysis, the tissues were separated and chopped with a meat grinder. Prior to analysis, chopped fish samples were kept at $-40^{\circ} \mathrm{C}$ for 48 hours in a freeze dryer. After drying, they were milled again and then separated into particles less than $0.2 \mathrm{~mm}$ mesh size and prepared for subsequent steps.

To investigate the performance of the investigated technique, detection and determination of phenol in fish muscle were tested. The results are shown in Table 2. These results show that the introduced procedure can be used for enrichment and determination of phenol in fish muscle. 
Table 1: Comparison of the published techniques for determination of phenolic compounds with the suggested protocol in this work

\begin{tabular}{ccccc}
\hline Method & Detection method & $\begin{array}{c}\text { LOD } \\
\left(\mu \mathrm{g} \mathrm{L}^{-1}\right)\end{array}$ & $\begin{array}{c}\text { Linear range } \\
\left(\mu \mathrm{g} \mathrm{L}^{-1}\right)\end{array}$ & Ref. \\
\hline SOPME & HPLC & 0.27 & $0.27-53.50$ & (Jiang et al. 2011) \\
IL- LLL- SBME & HPLC- UV & 0.1 & $0.5-50.0$ & (Guo \& Lee, 2011) \\
SPME & HPLC- UV & $2-4$ & $\mathrm{NM}$ & (Peñalver et al. 2002) \\
Capillary liquid & Electrochemical & & $3-50$ & (Segovia-Martnez et al. \\
chromatography & detection & 1 & $\mathrm{NM}$ & 2010) \\
SPE & HPLC- UV & $50-1000$ & (Saitoh et al. 2002) \\
RP- DLLME & UV- Vis & $15 \mu \mathrm{g} \mathrm{Kg}^{-1}$ & $50-1800 \mu \mathrm{g} \mathrm{Kg}^{-1}$ & (Ziyaadini et al. 2016) \\
RP- DLLME & UV- Vis & $12 \mu \mathrm{g} \mathrm{Kg}^{-1}$ & 20- $5000 \mu \mathrm{g} \mathrm{Kg}^{-1}$ & This work \\
\hline
\end{tabular}

NM, Not mentioned; SOPME, salting out phase separation microextration; IL- LLL- SBME, Ionic liquid three- phase liquid- liquid- liquid solvent bar microextraction.

Table 2: Determination of total phenols with proposed RP- DLLME in fish muscle of Chabahar Bay (Iran)

\begin{tabular}{lccc}
\hline \multicolumn{1}{c}{ Type of fish } & Percentage of dried fish & $\begin{array}{c}\text { Fish size } \\
(\mathrm{cm})\end{array}$ & $\begin{array}{c}\text { Phenol founded } \\
\left(\mu \mathrm{Kg}^{-1}\right)\end{array}$ \\
\hline Sphyraena genie & 75.6 & 37.8 & 0.063 \\
Otolithes ruber & 76.9 & 26.2 & 0.103 \\
Rastrelliger kangurta & 75.0 & 24.0 & 0.126 \\
Lutjanus johnii & 76.0 & 22.2 & 0.087 \\
Barbus Subquin (Cunciatus) & 75.0 & 37.8 & 0.148 \\
\hline
\end{tabular}

The result showed the significant difference between concentrations of total phenols in Barbat subquin (Cunciatus) with Rastrelliger kangurta and Lutjanus johnii of fish samples. Also, content difference of total phenols in $R$. kangurt and Sphyraena genie is significant. Content of target analyte in Barbut ubquin (Cunciatus) with Sphyraena genie and Lutjanus johnii was significant difference.

\section{Conclusions}

In this paper, a novel RP- DLLME method was successfully developed and tested for preconcentration and spectrophotometric determination of total phenols in the tissues of five fish species from Chabahar Bay. The linear range had a wide concentration and the RP- DLLME could selectively extract phenols for spectrophotometry determination even at low concentration. RP- DLLME has many advantages. For example, it is easy to extract with simple operation, is repeatable, allows rapid separation, costs less and has good selectivity in complex sample with good linearity in results.

\section{Acknowledgments}

We gratefully acknowledge financial support from the Research Council of Chabahar Maritime University. 


\section{References}

Akhtar, M., Bhanger, M.I., Iqbal, S., \& Hasany, S.M. 2006. Sorption potential of rice husk for the removal of 2,4-dichlorophenol from aqueous solutions: kinetic and thermodynamic investigations. Journal of Hazardous Material. 128: 44-52.

https://doi.org/10.1016/j.jhazmat.2005.07.025

Blanco, E., Casais, M.C., Mejuto, M.C., \& Cela, R. 2005. Analysis of tetrabromobisphenol A and other phenolic compounds in water samples by nonaqueous capillary electrophoresis coupled to photodiode array ultraviolet detection. Journal of Chromatography A. 1071: 205-211. https://doi.org/10.1016/j.chroma.2004.10.075

Feng, Q.Z., Zhao, L.X., Yan, W., Lina, J.M., \& Zheng, Z.X. 2009. Molecularly imprinted solidphase extraction combined with high performance liquid chromatography for analysis of phenolic compounds from environmental water samples. Journal of Hazardous Materials. 167: 282-288.

https://doi.org/10.1016/j.jhazmat.2008.12.115

Ghorbanpour, H., Yadeghari, A., Khoshmaramc, L., \& Farajzadeh, M.A. 2014. Air-assisted liquidliquid microextraction for simultaneous derivatization, extraction, and preconcentration of some phenolic compounds. Analytical Methods. 6: 7733-7743.

https://doi.org/10.1039/C4AY01254B

Guo, L., \& Lee, H.K. 2011. Ionic liquid based threephase liquid-liquid-liquid solvent bar microextraction for the determination of phenols in seawater samples. Journal of Chromatography

A. 1218: 4299-4306. https://doi.org/10.1016/j.chroma.2011.05.031

Hashemi, S.H., \& Najari, F. 2018. Response surface methodology of pre-concentration of chorophenols from seawater samples by molecularly imprinted stir bar sorptive extraction combined with HPLC: Box-Behnken design. Journal of Chromatographic Science. 57(3): 1-11.

https://doi.org/10.1093/chromsci/bmy107

Hashemi S.H., Kaykhaii M., \& Dehvari R. 2017. InSyringe Dispersive Liquid-Liquid Microextraction Coupled with High-Performance Liquid Chromatography for Trace Analysis of Naphthalene Sulfonates in Seawater. Current Chromatography. 4: 58-65.

https://doi.org/10.2174/2213240604666170118112 $\underline{615}$

Jiang, X., Zhang, H., \& Chen, X. 2011. Determination of phenolic compounds in water samples by HPLC following ionic liquid dispersive liquid-liquid microextraction and coldinduced aggregation. Microchimica Acta. 175: 341-346.

https://doi.org/10.1007/s00604-011-0672-6

Khezeli, T., \& Daneshfar, A. 2015. Monodisperse silica nanoparticles coated with gold nanoparticles as a sorbent for the extraction of phenol and dihydroxybenzenes from water samples based on dispersive micro-solid-phase extraction: Response surface methodology. Journal of Separation Science. 38: 2804-2812.

https://doi.org/10.1002/jssc.201500320

Liu, S., Xie, Q., Chen, J., Sun, J., He, H., \& Zhang, X. 2013. Development and comparison of two dispersive liquid-liquid microextraction techniques coupled to high performance liquid chromatography for the rapid analysis of bisphenol A in edible oils. Journal of Chromatography A. 1295: 16-23.

https://doi.org/10.1016/j.chroma.2013.04.054

Li, Y., Li, X., Li, Y., Qi, J., Bian, J., \& Yuan, Y. 2009. Selective removal of 2,4-dichlorophenol from contaminated water using non-covalent 
imprinted microspheres. Environmental Pollution. 157: $1879-1885$.

https://doi.org/10.1016/j.envpol.2009.01.014

Liu, S., Xie, Q., Chen, J., Sun, J., He, H., \& Zhang, X. 2013. Development and comparison of two dispersive liquid-liquid microextraction techniques coupled to high performance liquid chromatography for the rapid analysis of bisphenol A in edible oils. Journal of Chromatography A. 1295: 16-23.

https://doi.org/10.1016/j.chroma.2013.04.054

Masque, N., Marce, R.M., Borrull, F., Cormack, P.A.G., \& Sherrington, D. C. 2000. Synthesis and evaluation of a molecularly imprinted polymer for selective on-line solidphase extraction of 4nitrophenol from environmental water. Analytical Chemistry. 72: 4122-4126.

https://doi.org/10.1021/ac0000628

Mohsen, Z., Mohammad, R.G., \& Parviz, N. 2010. Dispersive liquid liquid microextraction followed by spectrofluorimetry as a simple and accurate technique for determination of thiamine (vitamin B-1). Microchimica Acta. 168: 317-324. https://doi.org/10.1007/s00604-009-0282-8

Nassiri, M., Kaykhaii M., Hashemi S.H., \& Sepahi M. 2018. Spectrophotometric Determination of Formaldehyde in Seawater Samples after in-situ Derivatization and Dispersive Liquid-Liquid Microextraction. Iranian Journal of Chemistry and Chemical Engineering. 37: 89-98.

Nassiri, M., Zahedi, M.M., Pourmortazavi, S. M., \& Yousefzade, M. 2014. Optimization of dispersive liquid-liquid microextraction for preconcentration and spectrophotometric determination of phenols in Chabahar Bay seawater after derivatization with 4-aminoantipyrine. Marine Pollution Bulletin. 86: 512-517.

https://doi.org/10.1016/j.marpolbul.2014.03.037
Peñalver, A., Pocurull, E., Borrull, F., \& Marcé, R.M. 2002. Solid-phase microextraction coupled to high-performance liquid chromatography to determine phenolic compounds in water samples. Journal of Chromatography A. 953: 79-87. https://doi.org/10.1016/S0021-9673(02)00113-9

Rezaee, M., Assadi, Y., Milani, M.R., Aghaee, E., Ahmadi, F., \& Berijani, S. 2006. Determination of organic compounds in water using dispersive liquid-liquid microextraction. Journal of Chromatography A. 1116: 1-9. https://doi.org/10.1016/j.chroma.2006.03.007

Saitoh, T., Nakayama, Y., \& Hiraide, M. 2002. Concentration of chlorophenols in water with sodium dodecylsulfate- $\gamma$-alumina admicelles for high-performance liquid chromatographic analysis. Journal of Chromatography A. 972: 205209.

https://doi.org/10.1016/S0021-9673(02)01118-4

Segovia-Martnez, L., Moliner-Martnez, Y., \& Campns-Falc, P. 2010. A direct capillary liquid chromatography with electrochemical detection method for determination of phenols in water samples. Journal of Chromatography A. 1217: 7926-7930.

https://doi.org/10.1016/j.chroma.2010.10.078

Yang, P., Li, H., Wang, H., Han, F., Jing, S., \& Yuan, C., et al. 2017. Dispersive liquid-liquid microextraction method for HPLC determination of phenolic compounds in wine. Food Analytical Methods. 10: 2383-2397. https://doi.org/10.1007/s12161-016-0781-2

Zhong, S., Tan, S.N., Ge, L., Wang, W., \& Chen, J. 2011. Determination of bisphenol A and naphthols in river water samples by capillary zone electrophoresis after cloud point extraction. Talanta. 85: 488-492.

https://doi.org/10.1016/j.talanta.2011.04.009 
Ziyaadini, M., Zahedi, M.M., \& Khosravinia, S. 2016. Ultrasound-assisted extraction combined with reverse phase-dispersive liquid-liquid micro extraction as a new approach for preconcentration and spectrophotometric determination of total phenol in marine sediments of Chabahar Bay. Marine Pollution Bulletin. 109: 104-109. https://doi.org/10.1016/j.marpolbul.2016.06.013 
